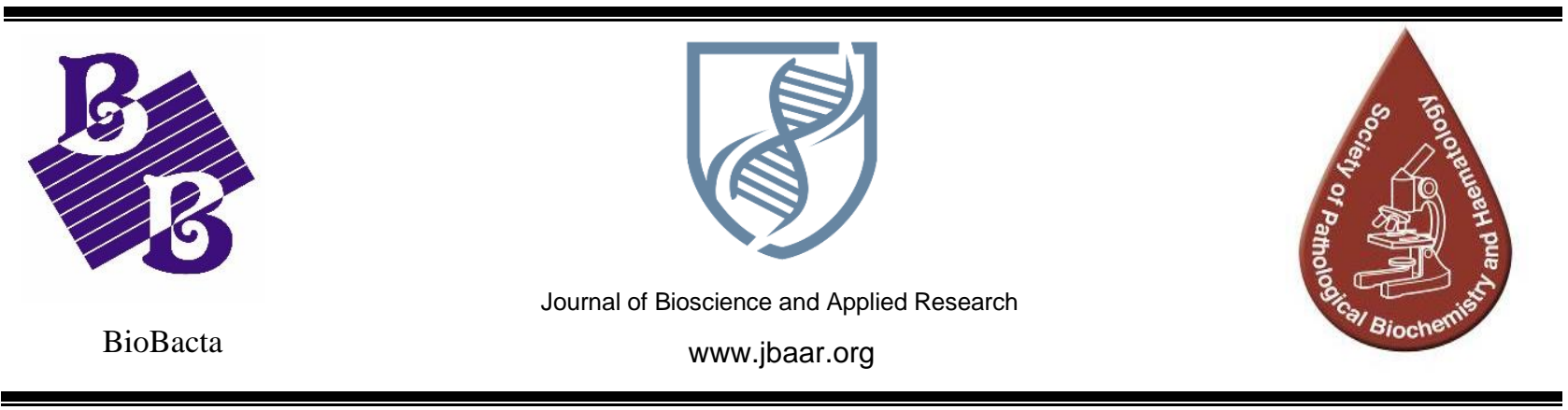

\title{
Downregulation of miR-23a and miR-24 in human hepatocellular carcinoma cells by Sorafenib via transforming growth factor-beta 1 in a SMAD dependent manner
}

\author{
Eman G. Ayad ${ }^{1}$, Mohga S. Abdulla*1, Hayat M. Sharada ${ }^{1}$, Abdel Hady A. Abdel Wahab ${ }^{2,}$ and \\ Abeer M. Ashmawy². \\ ${ }^{1}$ Department of Chemistry, Faculty of Science, Helwan University, Egypt. \\ ${ }^{2}$ Departments of Cancer Biology, National Cancer Institute, Cairo University, Egypt.
}

*Correspondence:

DOI: 10.21608/jbaar.2019.147398

Mohga S. Abdulla ${ }^{1}$, Ph.D.

Professor of Biochemistry and Former Chair of Chemistry Department, faculty of science, Helwan University

Chemistry Department, Faculty of Science, Helwan University, Ain Helwan, Cairo, Egypt, Cairo, postal code 11795

Telephone: $\quad$ +202 -0 1006607752 Email: drmohgashafik@yahoo.com

Received date: May 15, 2019. Accepted: August 5, 2019, Published: August 14, 2019

\begin{abstract}
:
MicroRNAs (miRNAs) are small non-coding RNAs that regulate gene expression through post-transcriptional interactions with mRNA. MiRNAs have recently been considered as key regulators of various cancers including liver cancer. Sorafenib is one of the antitumor drugs for the treatment of advanced hepatocellular carcinoma. It acts as a multikinase inhibitor suppressing cell proliferation and angiogenesis. This study tries to investigate a potential microRNA-based mechanism of action of the drug by studying the effect of sorafenib on miR-23a and miR-24 levels in HCC cell lines HepG2/Huh7 and revealing the possible drug mechanism against these oncogenic mi-RNAS in this study cell viability of cultured HepG2/Huh7 after treatment with sorafenib were evaluated using Sulphorhodamine-B (SRB) assay, cell cycle, and apoptosis estimated by flow cytometry assay. The caspase-3 level was determined using the ELISA assay. Moreover, miR-23a and miR-24 expression levels were analyzed by qPCR. Finally, TGF- $\beta$ levels and phosphorylated smad 2,3 were examined after treatment with sorafenib using ELISA and western blotting. Our data confirmed the Sorafenib inhibition of cell growth in both cell lines which
\end{abstract}


was accompanied by a significant increase in cell apoptosis and cell cycle arrest. Cells treated with sorafenib showed a significant decrease in miR-23a and miR-24 levels in both cell lines. Interestingly, the change in these oncogenic miRNAs was accompanied by a significant decrease of (TGF- $\beta 1$ ) and phosphorylated smad2, 3 protein levels. Our study suggested that inhibition of the tgf beta pathway in smad dependent manner could be the way characteristic of sorafenib to inhibit the oncogenic miR-23a and miR-24 levels in HCC.

Keywords: hepatocellular carcinoma cells, microRNAs, miR-23a, miR-24, sorafenib, TGF- $\beta 1$.

\section{INTRODUCTION}

Hepatocellular carcinoma (HCC), one of the most common malignant neoplasms in the digestive system and the fifth major cause of cancer-related mortality throughout the world, is characterized by a high prevalence of drug resistance and lack of curative treatment (Waly Raphael et al,.2012).

MicroRNAs (miRNAs) are a group of 17-25 nucleotide (nt) small non-coding RNAs that regulate the translational inhibition or degradation of target messenger RNAs (mRNAs) by binding to the $3^{\prime}$ untranslated region (3'UTR) of their target genes. (Bartel, 2004). Increasing evidence shows that miRNAs can act as oncogenes and tumor suppressors depending on tissue type and specific targets (Garzon et al., 2009; Kasinski et al., 2011).In recent decades; many studies have shown that miRNAs appear to be a major regulator of HCC. There are nearly 20 miRNAs that have been reported to regulate $\mathrm{HCC}$ tumor progression and metastasis by regulating key genes. (Yang et al., 2015).

Sorafenib is an oral drug acting as a multikinase inhibitor and represents the standard of care for advanced HCC (Llovet et al., 2008; Cheng et al., 2009). The molecule is endowed with antiproliferative and antiangiogenic properties that suppress tumor growth but its mechanism of action has not been fully elucidated yet (Wilhelm et al., 2006). On the other hand, various studies highlight changes in miRNA expression profiles in response to Sorafenib and other therapeutics (Peveling-Oberhag et al., 2015; Stiuso et al., 2015).
The aim of the current study to investigate the effect of Sorafenib on miR-23a and miR-24 expressions in HCC cell lines HepG2 /Huh7 using quantitative real-time polymerase chain reaction (qRT-PCR). Furthermore, we try to tackle a possible molecular mechanism by which sorafenib might affect miRNA-23a and miR-24 expression levels in HCC cells.

\section{MATERIAL AND METHODS}

\section{Regents}

Sorafenib was provided by the Bayer Corporation (West Haven, CT). For in vitro studies, for a $10 \mathrm{mM}$ stock, the $10 \mathrm{mg}$ reconstituted in $1.57 \mathrm{ml}$ DMSO. The final concentration of DMSO in the medium was $0.1 \%$ $(\mathrm{v} / \mathrm{v})$.

\section{Cell culture}

HepG2 and Huh7 human hepatocellular carcinoma cell lines were purchased from (National Holding Company for Biologics and Vaccines, Cairo, Egypt). The cells were cultured in Dulbecco's modified Eagle's medium (DMEM) supplemented with $10 \%$ heat-inactivated fetal bovine serum, $100 \mathrm{U} / \mathrm{mL}$ penicillin, and 100 $\mathrm{mg} / \mathrm{mL}$ streptomycin (Sigma-Aldrich Chemical Co., USA). All of the cells were cultured in a humidified atmosphere of $5 \% \mathrm{CO} 2$ in air at $37^{\circ} \mathrm{C}$.

\section{Cell viability assay}

Sulphorhodamine-B (SRB) assay was performed to assess the growth inhibition of Sorafenib to $\mathrm{HuH}-7$ and HepG2 hepatocellular carcinoma cells, cells were seeded in 96-well cell culture plates at the density of 5 $\times 10^{3}$ cells for $24 \mathrm{~h}$ and then exposed to different concentrations of Sorafenib $(0,2,2.5,5$, and $10 \mu \mathrm{g} / \mathrm{ml})$ 
for $48 \mathrm{~h}$. Control cells received 0.1\% DMSO. Subsequently, the cells were fixed by adding to each well $100 \mu \mathrm{l}$ of cold trichloroacetic acid $(10 \%$ (w/v)) and incubating for $60 \mathrm{~min}$ at $4{ }^{\circ} \mathrm{C}$. The plates were then washed five times with de-ionized water and air-dried. Each well was then stained with $50 \mu 1$ of $0.4 \%$ SRB (Sigma-Aldrich Chemical Co., USA) for $10 \mathrm{~min}$. Unbound SRB was removed by washing five times with $1 \%$ acetic acid. After dried, the bound stain was solubilized with $100 \mu 1$ of $10 \mathrm{mM}$ Tris base ( $\mathrm{pH} 10.5$ ) and the optical density of each well was determined with a spectrophotometer at $570 \mathrm{~nm}$. Four duplicate wells were set up for each concentration sample.

\section{Cell apoptosis analysis}

After $48 \mathrm{~h}$ treatment in a 6-well plate's cells were collected and centrifuged at $300 \times \mathrm{g}$ for 10 minutes. After washing twice with PBS and centrifuging in the same condition, cells were stained with $10 \mu \mathrm{L}$ of Annexin V-FITC (BestBio, Shanghai, People's Republic of China) for 15 minutes and $5 \mu \mathrm{L}$ of PI for 5 minutes at $4^{\circ} \mathrm{C}$ in the dark. Cells were then analyzed using FITC signal detector and PI detector with Epics XL flow cytometry. (Beckman Coulter, USA) and The Analysis is done Flowing software version 2.5.1 (Turka center of biotechnology, Turka uni, Finland). A minimum of $2 \times 10^{4}$ cells was analyzed for each sample. All experiments were repeated at least three times

\section{Cell cycle assay}

After $48 \mathrm{~h}$ treatment in 6-well plates, the cells were harvested and washed twice with cold PBS. Cells were fixed in $75 \%$ ethanol at $4 \mathrm{c}$ overnight. Staining for DNA content was performed with $50 \mu \mathrm{g} / \mathrm{ml}$ propidium iodide and $50 \mu \mathrm{g} / \mathrm{ml}$ ribonuclease $\mathrm{A}$ at $4^{\circ} \mathrm{C}$ for $30 \mathrm{~min}$ in the dark. Populations in G0 /G1, S, and G2/M phases were analyzed by FACS (Beckman Coulter, USA). Data were collected and analyzed with flowing software version 2.5.1 (Turka center of biotechnology, Turka uni, Finland).

\section{Western blot analysis}

After treatment with Sorafenib for $48 \mathrm{~h}$, the cells were lysed in 1\% Triton X-100 lysis buffer. Protein was subjected to $10 \%$ SDS-PAGE and transferred to PVDF membrane After blocked in 5\% nonfat milk membrane was incubated with mouse anti- Smad2, 3 phosphorylated McAb (R\&D SYSTEMS, biotech, S465/S467, dilution 1:200)., or Beta-actin (Sigma Aldrich, A4700, dilution 1:5000). The Primary antibodies were detected using HRP-conjugated antirabbit secondary antibody (1:10000 dilutions, (Sigma Chemical, USA). The Signals were detected with HRP conjugated secondary antibody visualized using an enhanced chemiluminescence (ECL) system.

\section{Enzyme-linked immune sorbent assay}

After treatment with Sorafenib for $48 \mathrm{~h}$; the cell culture supernatant was harvested at the indicated time-points. The concentrations of TGF $\beta 1$ in the medium were measured by a TGF $\beta 1$ enzyme-linked immunosorbent assay (ELISA) kit (DRG® International, USA). Also, cell pellets were collected and lysed for detection of caspases3 levels measured by the MyBioSource kit (CA, USA). All samples were assayed in triplicate.

\section{Quantitative RT-PCR}

Total RNA was extracted using Qizol (Qiagen, Germany) according to the manufacturer's protocol. Quantification of Mature miR-23a and miR-24 expressions proceeded by isolation of total RNA followed by polyadenylation and reverse transcription for use in a one-step quantitative RT-PCR. The complementary DNA from the miRNA was synthesized using miScript II cDNA Synthesis Kit (Qiagen, Germany) Real-time PCR analyses were performed with Real Master Mix (SYBR Green, Qiagen) using synthesized primers that were purchased from (Qiagen, Germany). U6 small nuclear RNA was used as an internal normalized reference; the foldchanges of miR-23a and miR-24 were calculated using the $2^{-\Delta \Delta \mathrm{Ct}}$ method.

\section{Statistical analysis}


All statistical analyses were performed using Spss software, version 14. DATA SPSS INC., IBM, CHICAGO, United States Of America. Obtained from three or more individual experiments were expressed as mean \pm SD. data were analyzed by a one-way ANOVA test. P-values less than 0.05 were considered statistically significant

\section{RESULTS}

\section{Effect of Sorafenib on Cell Growth}

HepG2 and Huh-7 cells treated cells with Sorafenib showed a significant response. As shown in Figure 1 after a treatment period of $48 \mathrm{~h}$, Sorafenib produced a concentration-dependent decrease in cell viability of both cell lines compared to the non-treated control. The $50 \%$ inhibition concentration value (IC 50) of Sorafenib on Hepg2 and Huh7 was $5 \mu \mathrm{g} / \mathrm{ml}$ and $6.5 \mu \mathrm{g} / \mathrm{ml}$ respectively. Indicating that Sorafenib exhibits a potent anti-cancer action at a low dose.

\section{Effects of Sorafenib on Expression of miR-23a and miR-24}

In the current study, we investigated whether Sorafenib influences the expression level of miR-23a and miR-24 for both cell lines using quantitative RTPCR assay. A significant decrease of miR-23a and miR-24 was reported for both cell lines after treatment with sorafenib where the fold changes for miR-23a/ miR-24 for HepG2 were, $0.73 \pm 0.04$ and $0.053 \pm 0.23$ respectively while in Huh-7 were $0.5 \pm 0.18$ and $0.032 \pm 0.4$ compared to the control $\mathrm{P}<0.05$ as shown in Figure 2

\section{Effects of Sorafenib on apoptosis and cell cycle}

The induction of apoptosis by sorafenib was further evaluated by flow cytometry (figure 3 ). the output data demonstrated in both of hepg2 and huh7 cells a significant increase in the Annexin $\mathrm{V}+\mathrm{Pi}+$ population (late apoptotic cells) by (9 \%and $18.6 \%),(\mathrm{p}<0.05)$ respectively compared to control. Moreover, analysis of the cell cycle distribution showed a significant decrease in the number of cells in s phase in hepg 2 and huh7 cells by $(9.09 \%$ and $14.5 \%)$ respectively ( $\mathrm{p}<$ 0.05 ) after sorafenib treatment for 48 hours in comparison with untreated cells (figure 4).

\section{Effect of Sorafenib on caspase-3}

Caspase- 3 levels were measured at the established time after sorafenib treatment hepg 2 and huh7 plated cells. The results revealed that sorafenib induced a significantly higher increase in the level of caspase 3 (figure 5) in respect to untreated cells $\mathrm{p}<0.05$ which indicates that sorafenib induces apoptosis through the intrinsic pathway.

\section{Sorafenib Inhibits the Expression of Phosphorylated Smad2, 3 and TGF beta in HCC cells}

Western blotting and ELISA assays were performed to assess the protein levels of $\mathrm{p}-\mathrm{Smad} 2,3$, and TGF $\beta 1$ respectively in HepG2 and Huh-7 cells. Significant downregulation of phospho- SMAD2, 3 levels was observed in both Hepg2 and Huh7 after treatment with two different doses of Sorafenib comparing to the control (untreated) cells. Using software for photo analysis, the results indicated a decrease in phosphoSMAD2, 3 in Hepg2 treated with 2.5 and $5 \mu \mathrm{g} / \mathrm{ml}$ of sorafenib by $63.3 \%$ and $90.5 \%(\mathrm{P}<0.01)$ respectively. Furthermore, in Huh7 cells, the percentages of downregulation recorded were $35.3 \%(\mathrm{P}<0.05)$ and $97.1 \%$ $(\mathrm{P}<0.01)$ for doses 3.2 and $6.5 \mu \mathrm{g} / \mathrm{ml}$ respectively as shown in figures 6 and 7. Moreover, a significant downregulation in TGF $\beta 1$ level was observed in both treated cell lines in a dose-dependent manner $(\mathrm{P}<0.05)$ as described in figures 8 and 9 


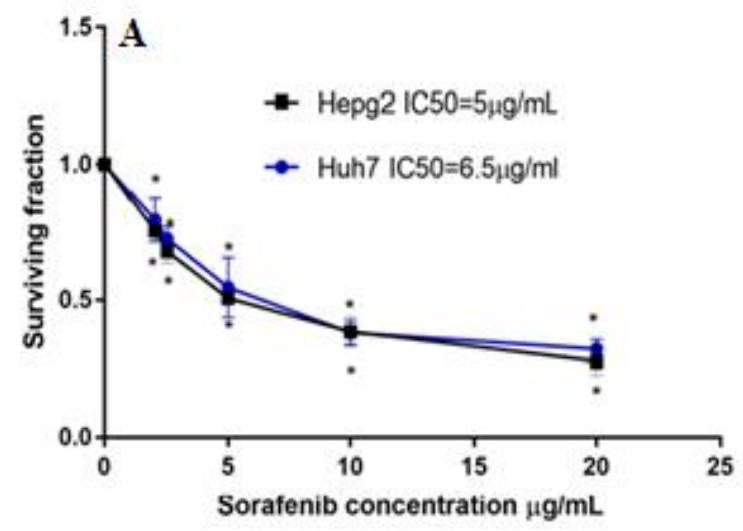

B

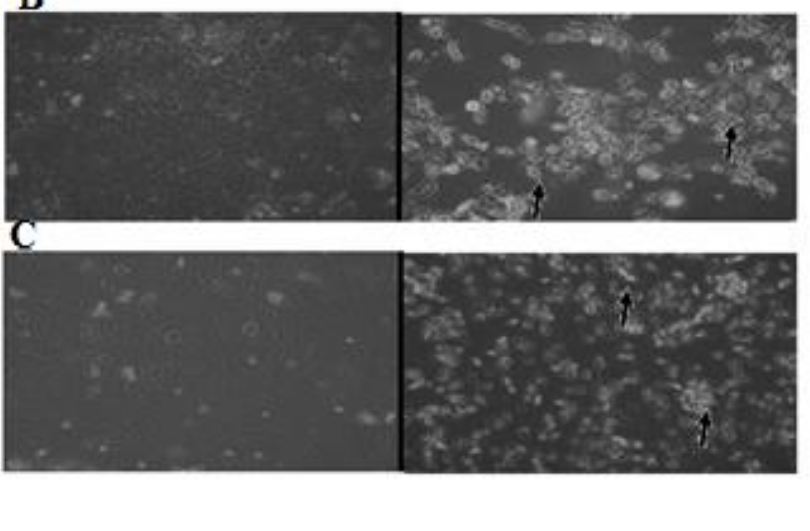

Fig1: Effect of Sorafenib on the viability of HepG2 and Huh-7 cells were treated with Sorafenib at different concentrations for $48 \mathrm{~h}$, and the results were expressed by percentages of surviving cells over untreated control cells using the SRB assay. The values are presented as mean \pm SD for three independent experiments. (A) Sorafenib inhibited the cell growth of HepG2 and Huh-7 in a dose-dependent manner (B) Morphological changes Of HepG2 cells after treatment with Sorafenib (C) Morphological changes Of Huh-7 cells after treatment with Sorafenib. Arrow represents volume loss, chromatin clumping, and cell shrinkage.

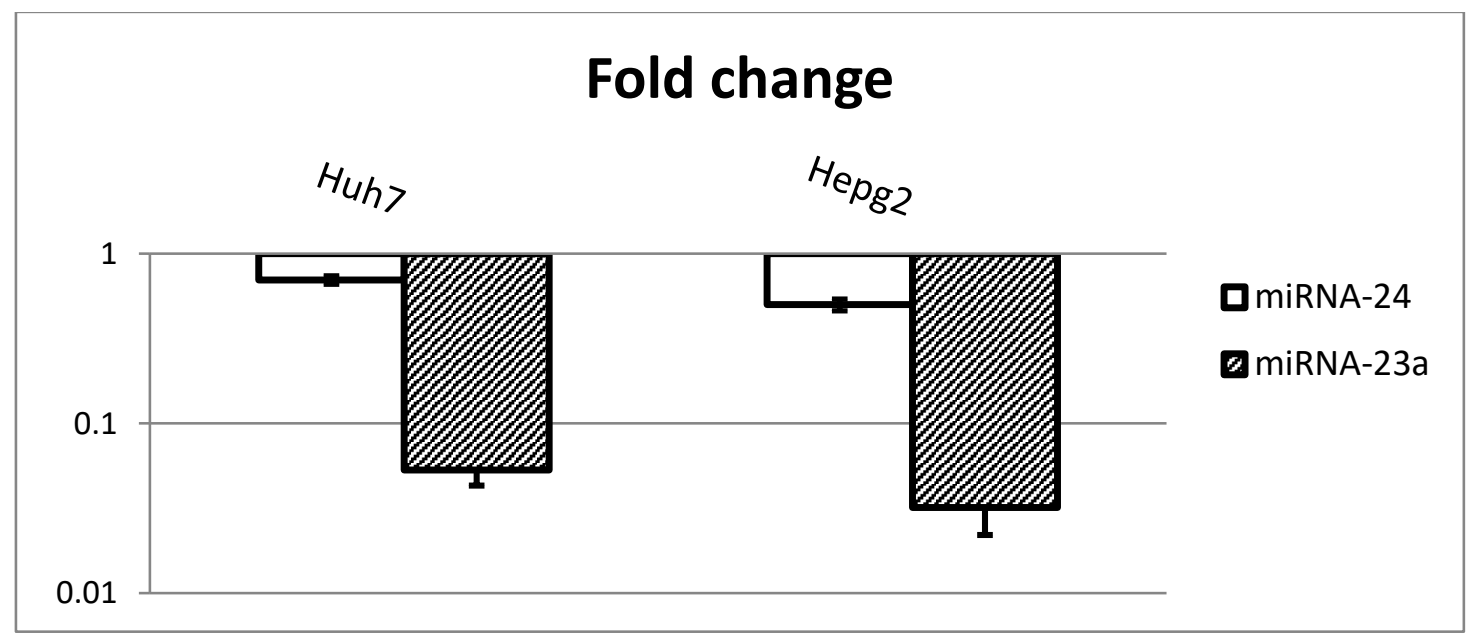

Fig.2: Expression levels of miR-23a and miR-24in hepatocellular carcinoma cells with treatment of Sorafenib 


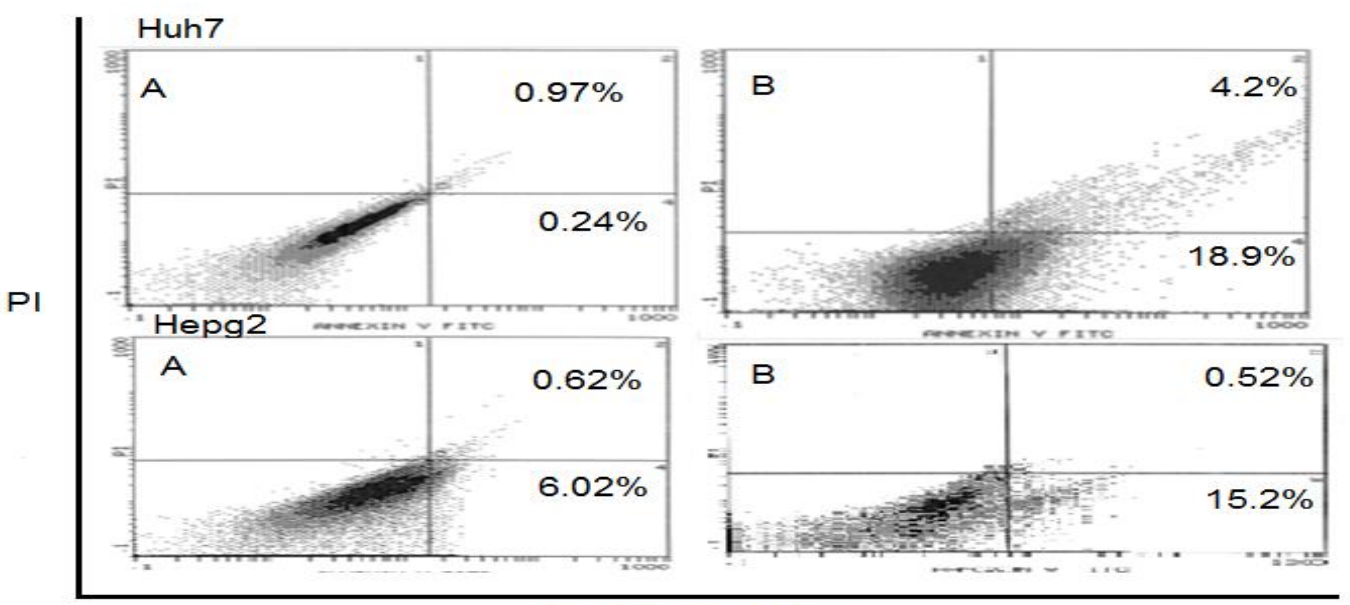

ANNEVIN $\vee$ FITC

Fig. 3: Flow cytometric evaluation of Hepg 2 and huh7 apoptosis. Histograms derived from flow cytometry comparing apoptotic cells between A) untreated and B) treated cells with sorafenib. After treatment for 48hrs, the induction of apoptosis determined using Flow analysis of Annexin V-FITC and PI-stained Hepg2 and huh7, cells in the lower right quadrant indicate Annexin-positive/ PI-negative as early apoptotic cells while cells in the upper right quadrant indicate Annexin-positive/PI-positive as late apoptotic cells.
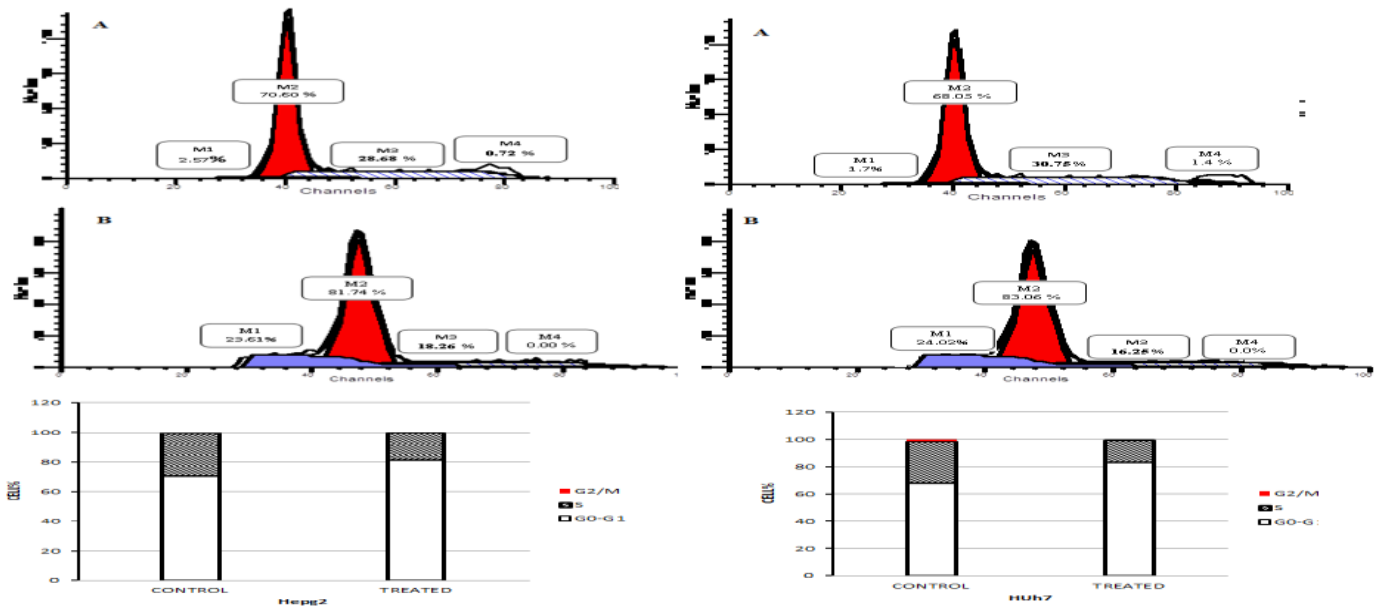

Fig. 4: Cell cycle analysis of treated Hepg2 and Huh7 with sorafenib. A decrease in S Phage accompanied by a significant increase in G1 phase and apoptosis was observed in Cells treated with Sorafenib (A) compared to untreated (B). (MI=Apoptosis, M2=G0/G1 phase [G0 (quiescence state), G1 (GAP1 phase)], M3= S phase [Synthetic phase], M4=G2/M phase [G2 (GAP1 phase), M (Mitosis)]). 


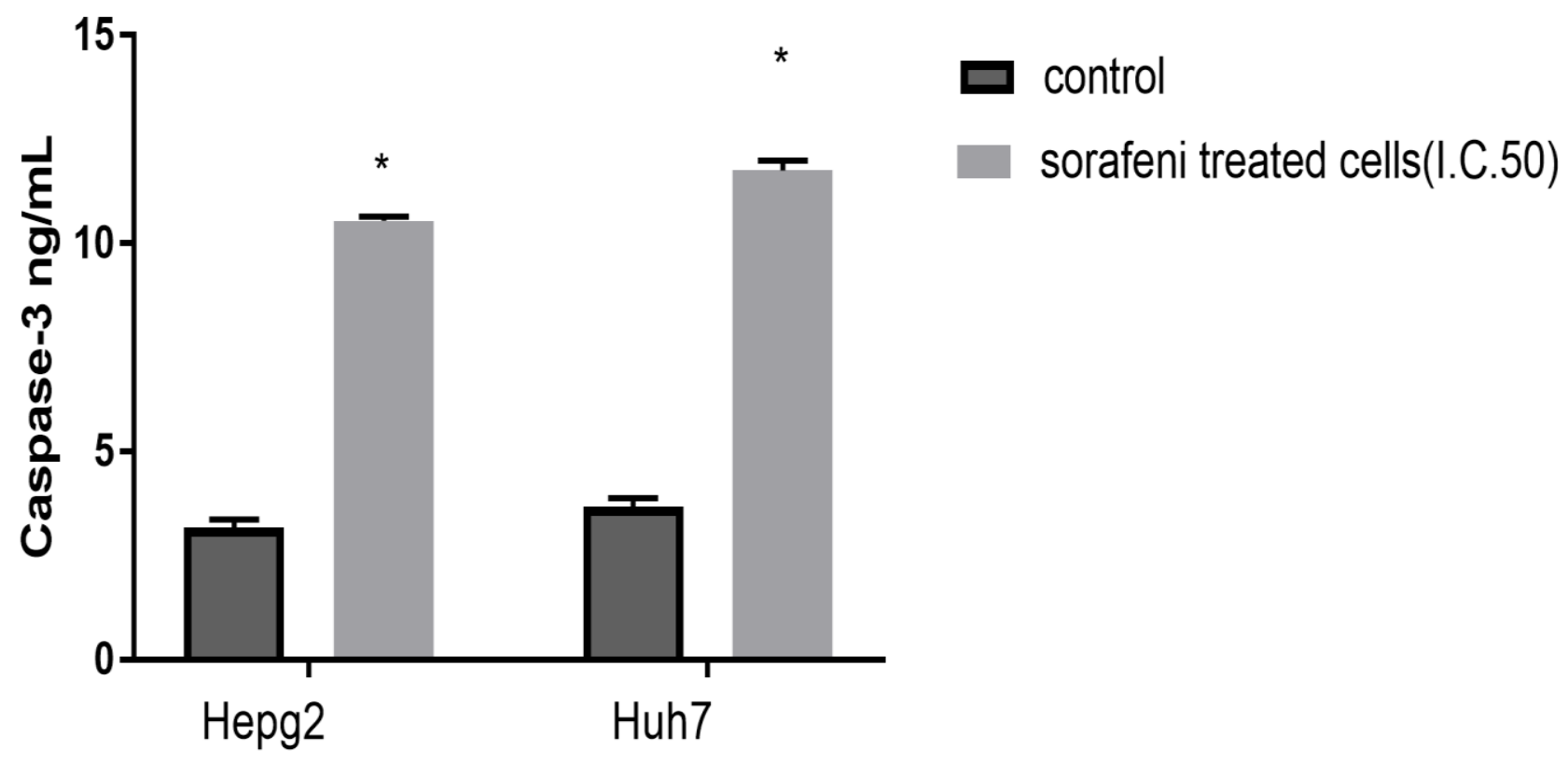

Fig.5: Effect of sorafenib treatment on Caspase 3 level in HepG2 and Huh7 for 48h. The results are the mean \pm SD of 3 separate experiments. Statistical significance of results was analyzed using one way ANOVA. * Significantly different from control, $(\mathrm{P}<0.05)$

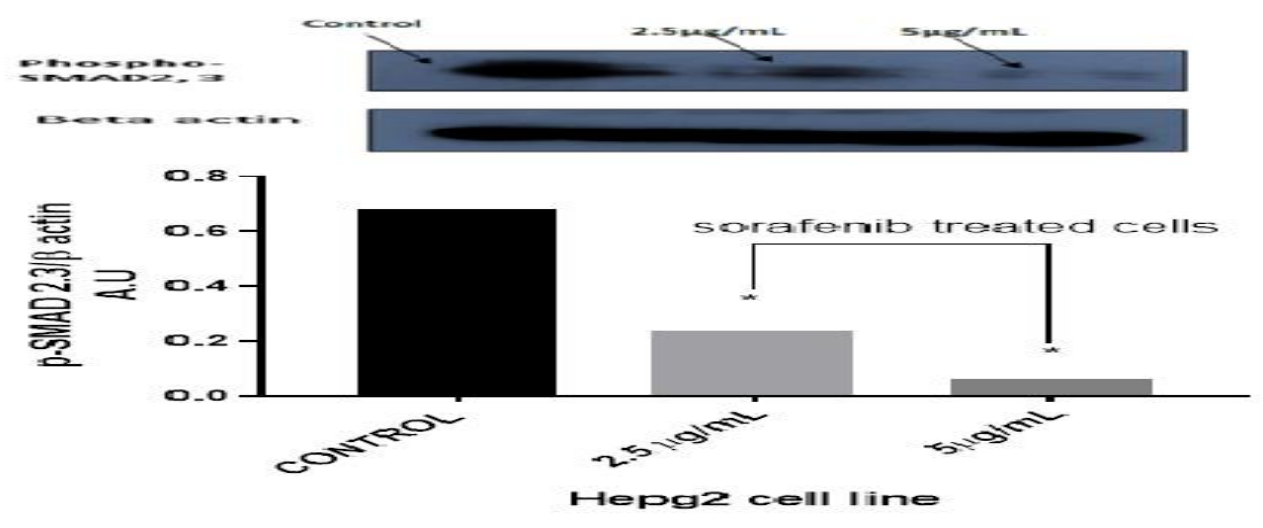

Fig. 6: Effects of two variable doses of $\operatorname{sorafenib}(2.5$ and $5 \mu \mathrm{g} / \mathrm{ml})$ on phosphorylated Smad 2, 3 protein level following $48 \mathrm{~h}$ exposure in Hepg2 cells using Western blotting technique. Statistical significance of results was analyzed using one way ANOVA. * Significantly different from control, $\quad(\mathrm{P}<0.05)$ 


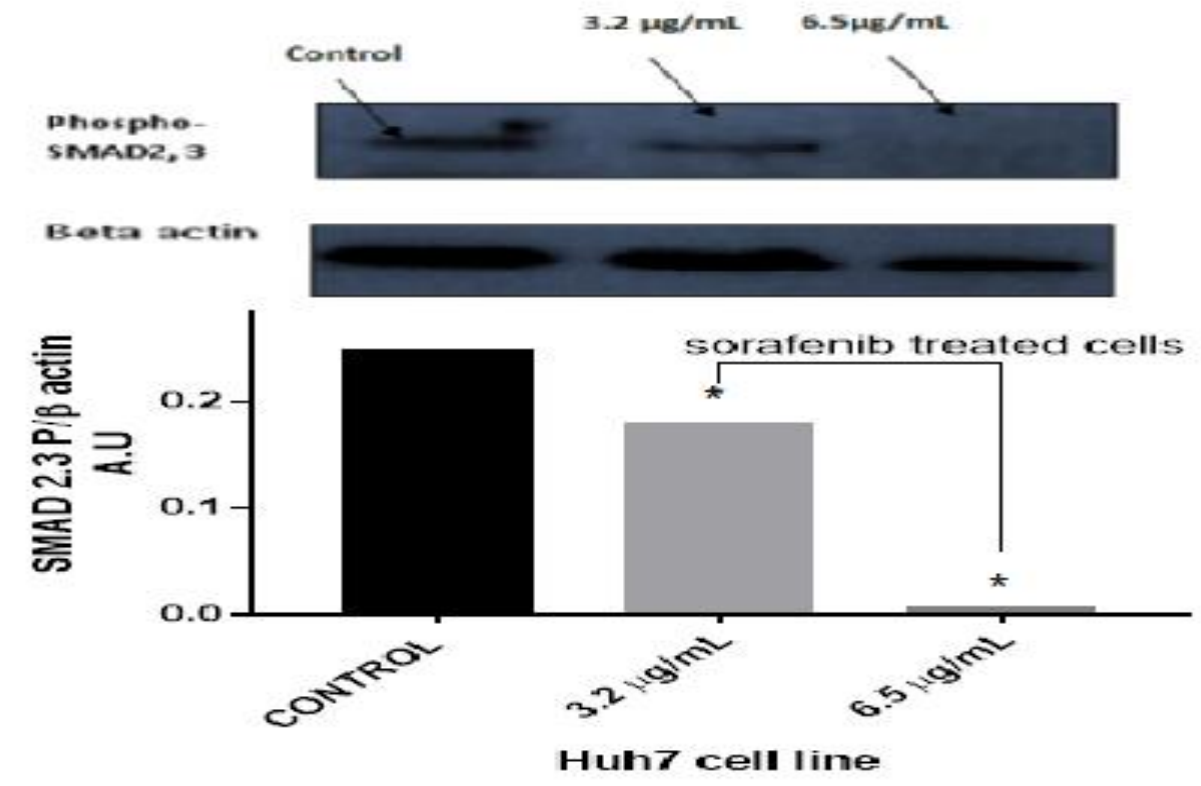

Fig.7: Effects of two variable doses of sorafenib $(3.2$ and $6.5 \mu \mathrm{g} / \mathrm{ml})$ on phosphorylated Smad 2, 3 protein level following $48 \mathrm{~h}$ exposure in Huh72 cells using the Western blotting technique. Statistical significance of results was analyzed using one way ANOVA. * Significantly different from control, $\quad(\mathrm{P}<0.05)$

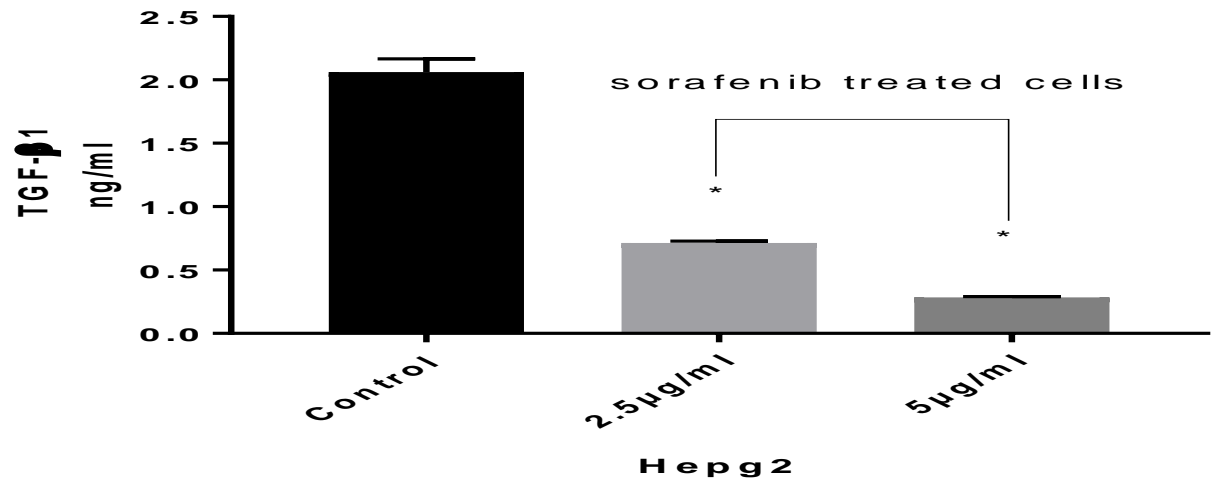

Fig. 8: Effects of two variable doses of sorafenib $(2.5$ and $5 \mu \mathrm{g} / \mathrm{ml})$ on TGF beta levels level following $48 \mathrm{~h}$ exposure in Hepg2 cells using ELISA technique. The results are the mean \pm SD of 3 separate experiments. Statistical significance of results was analyzed using one way ANOVA. * Significantly different from control, (P $<0.05)$ 


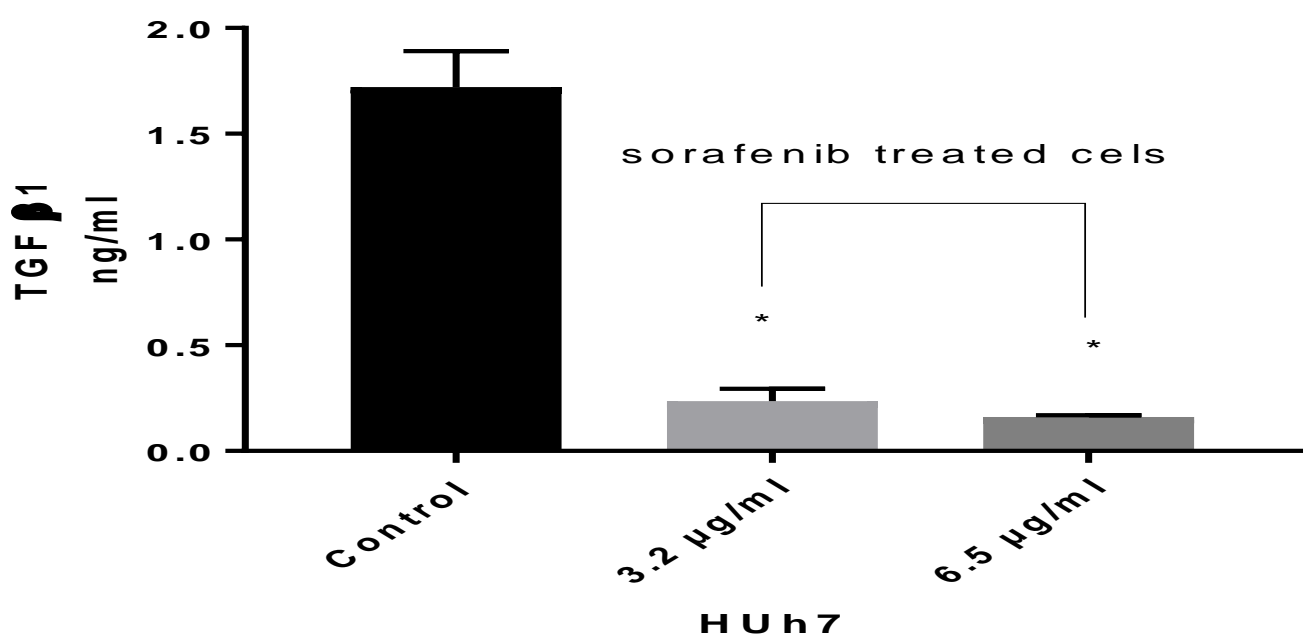

Fig. 9:Effects of two variable doses of sorafenib $(3.2$ and $6.5 \mu \mathrm{g} / \mathrm{ml})$ on TGF beta levels protein level following $48 \mathrm{~h}$ exposure in Huh72 cells using ELISA technique. The results are the mean \pm SD of 3 separate experiments. Statistical significance of results was analyzed using one way ANOVA. * Significantly different from control, (P $<0.05)$

\section{Discussion}

Hepatocellular carcinoma (HCC) is one of the most common cancers and represents the third-leading cause of cancer-related death worldwide (El-Serag et al., 2008; Jemal et al., 2011)

Sorafenib is the first oral multi-kinase inhibitor that targets Raf kinases to be developed, also inhibits the activity of several cellular kinases: The serine/threonine kinases c-Raf (Raf-1) and B-Raf; platelet-derived growth factor receptors; VEGF receptors; the cytokine receptor c-KIT; the receptor tyrosine kinases Flt-3 and RET; the Janus kinase/signal transducer and activator of transcription (JAK/STAT); the mitogen-activated protein kinases MEK and ERK (de La Coste et al., 1998; Hwang et al., 2004; Avila et al., 2006; Carlomagno et al., 2006; Wilhelm et al., 2008 ).

The molecular mechanism(s) by which sorafenib exerts its antitumor activity has not been fully elucidated; Recent data indicate that sorafenib induces changes in miRNA expression profiles considering a potential involvement of miRNAs in the antiproliferative activity of sorafenib. (Shimizu et al., 2010; Lv et al., 2015)

Emerging data showed that miR-24 cluster's members (miR-23a, miR-27a, and miR-24) were up-regulated and could serve as potential oncogenes in distinct cancer types, including pancreatic, gastric, ovarian, breast, and lung cancers. They can function as antiapoptotic and proliferation-promoting factors in liver cancer cells because their expressions are highly upregulated in hepatocellular carcinoma tissues compared with normal liver (Chhabra et al., 2010). Moreover, an interesting study indicated that miR-24 cluster members (miR-23a, miR-27a, and miR-24) levels were induced in response to TGF- $\beta 1$ in human hepatocellular carcinoma cells (Huh-7) in a SMADdependent manner. (Butz et al., 2012)

In this study we confirmed the cytotoxic effect of Sorafenib on HCC cells Hepg2 and Huh7, we have demonstrated the effect of Sorafenib on apoptosis and cell cycle as sorafenib induced apoptosis level via increased Caspase 3 which also confirmed by flow cytometry. Cell cycle profile did indicate a classical arrest in the $S$ phase, Previous results had indicated that sorafenib might induce apoptosis through MCL1 
down-regulation and up-regulation of BIM which mediate activation of the intrinsic pathway in tumor cells. (Yu et al., 2006; Zhang et al., 2008)

Looking for a potential microRNA-based mechanism of action of the sorafenib. In this study the treatment of in cultured HepG2 and Huh7 hepatocellular carcinoma cells with Sorafenib caused a significant downregulation of miR-23a and miR-24 expressions compared to untreated control cells with variable fold changes where miR-23a showed more inhibition levels in response to the sorafenib in both cell lines compared with miR-24 expressions, Not only this study but also Bai et al. showed that the intervention of sorafenib might influence the expression profiling of miRNAs in HCC cells (Bai et al., 2009 ).

The multifunctional cytokine transforming growth factor- $\beta$ (TGF- $\beta$ ) orchestrates an intricate signaling network to modulate tumorigenesis and progression by exerting a dynamic effect on cancer cells. ( Massagu,2008) Previous studies have shown that TGF$\beta 1$ was overexpressed in HCC cells, and clinical studies showed higher blood levels of TGF- $\beta 1$ in patients with $\mathrm{HCC}$ than in patients with chronic hepatitis or cirrhosis. (Lin et al., 2015) Furthermore, TGF- $\beta 1$ exhibited a defining role in the regulation of the oncogenic miR-24 cluster members in HCC (Huang et al., 2008).

In this study, we evaluated the effect of Sorafenib on TGF- $\beta 1$ and phosphorylated SMAD 2, 3 levels in HepG2 and Huh7 cell lines the results demonstrated a significant decrease in TGF- $\beta 1$ and phosphorylated SMAD 2, 3 levels in both cell lines in a dose-dependent manner. Changes in TGF- $\beta 1$ level in response to sorafenib treatment in HCC cell lines were reported by Kang, et al; (Kang et al., 2017). Moreover, Jia et al reported a significant downregulation in phosphorylated SMAD 2, 3 levels in NRK-52E kidney cells by sorafenib treatment ( Jia et al.,2015) These results suggested that Sorafenib could inhibit the oncogenic miR-24 cluster's members (miR-23a, and
miR-24) in HCC most probably by controlling TGF- $\beta 1$ pathway in SMAD dependent manner.

The present study work contributes to the intellect of the mechanism of action of Sorafenib, an important drug for the treatment of hepatocellular carcinoma, spotting on a miRNA-based pathway that explains its antiproliferative activity. This knowledge may also be useful for conducting new therapeutic and prognostic strategies for HCC.

\section{References}

Avila, M. A., Berasain, C., Sangro, B., \& Prieto, J. (2006). New therapies for hepatocellular carcinoma. Oncogene, 25(27), 3866.

Bai, S., Nasser, M. W., Wang, B., Hsu, S. H., Datta, J., Kutay, H., et al. (2009). MicroRNA-122 inhibits tumorigenic properties of hepatocellular carcinoma cells and sensitizes these cells to sorafenib. The Journal of Biological Chemistry, 284(46), 32015-32027. doi:10.1074/jbc.M109.016774 [doi]

Bartel, D. P. (2004). MicroRNAs: Genomics, biogenesis, mechanism, and function. Cell, 116(2), 281-297.

\section{Butz, H., Rácz, K., Hunyady, L., \& Patócs, A.} (2012). Crosstalk between TGF- $\beta$ signaling and the microRNA machinery. Trends in Pharmacological Sciences, 33(7), 382-393.

\section{Butz, H., Rácz, K., Hunyady, L., \& Patócs, A.} (2012). Crosstalk between TGF- $\beta$ signaling and the microRNA machinery. Trends in Pharmacological Sciences, 33(7), 382-393.

Carlomagno, F., Anaganti, S., Guida, T., Salvatore, G., Troncone, G., Wilhelm, S. M., et al. (2006). BAY 43-9006 inhibition of oncogenic RET 
mutants. Journal of the National Cancer

Institute, 98(5), 326-334.

Cheng, A., Kang, Y., Chen, Z., Tsao, C., Qin, S.,

Kim, J. S., et al. (2009). Efficacy and safety of sorafenib in patients in the Asia-pacific region with advanced hepatocellular carcinoma: A phase III randomised, double-blind, placebocontrolled trial. The Lancet Oncology, 10(1), 2534.

Chhabra, R., Dubey, R., \& Saini, N. (2010). Cooperative and individualistic functions of the microRNAs in the miR-23a 27a 24-2 cluster and its implication in human diseases. Molecular Cancer, 9(1), 232.

de La Coste, A., Romagnolo, B., Billuart, P., Renard, C. A., Buendia, M. A., Soubrane, O., et al. (1998). Somatic mutations of the betacatenin gene are frequent in mouse and human hepatocellular carcinomas. Proceedings of the National Academy of Sciences of the United States of America, 95(15), 8847-8851.

\section{El-Serag, H. B., Marrero, J. A., Rudolph, L., \&}

Reddy, K. R. (2008). Diagnosis and treatment of hepatocellular carcinoma. Gastroenterology, 134(6), 17521763.

Garzon, R., Calin, G. A., \& Croce, C. M. (2009). MicroRNAs in cancer. Annual review of medicine, 60, 167-179.

Huang, S., He, X., Ding, J., Liang, L., Zhao, Y., Zhang, Z., et al. (2008). Upregulation of miR23a 27a 24 decreases transforming growth factor-beta-induced tumor-suppressive activities in human hepatocellular carcinoma cells. International Journal of Cancer, 123(4), 972978.
Huang, C., Jacobson, K., \& Schaller, M. D. (2004). MAP kinases and cell migration. Journal of Cell Science, 117(Pt 20), 4619-4628. doi:10.1242/jcs.01481 [doi]

Jemal, A., Bray, F., Center, M. M., Ferlay, J., Ward, E., \& Forman, D. (2011). Global cancer statistics. CA: a cancer journal for clinicians, 61(2), 69-90.

Jia, L., Ma, X., Gui, B., Ge, H., Wang, L., Ou, Y. \& Fu, R. (2015). Sorafenib ameliorates renal fibrosis through inhibition of TGF- $\beta$-induced epithelial-mesenchymal transition. PLoS One, 10(2), e0117757.

Kang, D., Han, Z., Oh, G. H., Joo, Y., Choi, H. J., \& Song, J. J. (2017). Down-Regulation of TGF$\beta$ Expression Sensitizes the Resistance of Hepatocellular Carcinoma Cells to Sorafenib. Yonsei medical journal, 58(5), 899909.

Kasinski, A. L., \& Slack, F. J. (2011). MicroRNAs en route to the clinic: progress in validating and targeting microRNAs for cancer therapy. Nature Reviews Cancer, 11(12), 849.

Liu, F., Dong, X., Lv, H., Xiu, P., Li, T., Wang, F., et al. (2015). Targeting hypoxia-inducible factor$2 \alpha$ enhances sorafenib antitumor activity via $\beta$ catenin/C-myc-dependent pathways in hepatocellular carcinoma. Oncology Letters, 10(2), 778-784.

Llovet, J. M., Ricci, S., Mazzaferro, V., Hilgard, P., Gane, E., Blanc, J., et al. (2008). Sorafenib in advanced hepatocellular carcinoma. New England Journal of Medicine, 359(4), 378-390.

Shimizu, S., Takehara, T., Hikita, H., Kodama, T., Miyagi, T., Hosui, A., et al. (2010). The let-7 family of microRNAs inhibits bcl-xL expression 
and potentiates sorafenib-induced apoptosis in human hepatocellular carcinoma. Journal of Hepatology, 52(5), 698-704. doi:10.1016/j.jhep.2009.12.024

Stiuso, P., Potenza, N., Lombardi, A., Ferrandino, I., Monaco, A., Zappavigna, S., et al. (2015). MicroRNA-423-5p promotes autophagy in cancer cells and is increased in serum from hepatocarcinoma patients treated with sorafenib. Molecular Therapy-Nucleic Acids, 4

\section{Waly Raphael, S., Yangde, Z., \& YuXiang, C.} (2012). Hepatocellular carcinoma: Focus on different aspects of management. ISRN Oncology, 2012

Wilhelm, S., Carter, C., Lynch, M., Lowinger, T., Dumas, J., Smith, R. A., et al. (2006).

Discovery and development of sorafenib: A multikinase inhibitor for treating cancer. Nature Reviews Drug Discovery, 5(10), 835.

\section{Wilhelm, S. M., Adnane, L., Newell, P., Villanueva,} A., Llovet, J. M., \& Lynch, M. (2008). Preclinical overview of sorafenib, a multikinase inhibitor that targets both Raf and VEGF and PDGF receptor tyrosine kinase signaling. Molecular Cancer Therapeutics, 7(10), 31293140. doi:10.1158/1535-7163.MCT-08-0013 [doi]
Yang, J. D., \& Roberts, L. R. (2010). Hepatocellular carcinoma: A global view. Nature Reviews Gastroenterology and Hepatology, 7(8), 448.

Yang, N., Ekanem, N. R., Sakyi, C. A., \& Ray, S. D. (2015). Hepatocellular carcinoma and microRNA: New perspectives on therapeutics and diagnostics. Advanced Drug Delivery Reviews, 81, 62-74.

Yang, N., Ekanem, N. R., Sakyi, C. A., \& Ray, S. D. (2015). Hepatocellular carcinoma and microRNA: New perspectives on therapeutics and diagnostics. Advanced Drug Delivery Reviews, 81, 62-74.

Yu, C., Friday, B. B., Lai, J. P., Yang, L., Sarkaria, J., Kay, N. E., et al. (2006). Cytotoxic synergy between the multikinase inhibitor sorafenib and the proteasome inhibitor bortezomib in vitro: Induction of apoptosis through akt and c-jun NH2-terminal kinase pathways. Molecular Cancer Therapeutics, 5(9), 2378-2387. doi:5/9/2378 [pii]

Zhang, W., Konopleva, M., Ruvolo, V., McQueen, T., Evans, R., Bornmann, W., et al. (2008). Sorafenib induces apoptosis of AML cells via bim-mediated activation of the intrinsic apoptotic pathway. Leukemia, 22(4), 808. 